\title{
The effect of regional sea level atmospheric pressure on sea level variations at globally distributed tide gauge stations with long records
}

https://doi.org/10.1515/jogs-2018-0007

Received November 7, 2017; accepted March 5, 2018

\begin{abstract}
This study provides additional information about the impact of atmospheric pressure on sea level variations. The observed regularity in sea level atmospheric pressure depends mainly on the latitude and verified to be dominantly random closer to the equator. It was demonstrated that almost all the annual and semiannual sea level variations at 27 globally distributed tide gauge stations can be attributed to the regional/local atmospheric forcing as an inverted barometric effect. Statistically significant non-linearities were detected in the regional atmospheric pressure series, which in turn impacted other sea level variations as compounders in tandem with the lunar nodal forcing, generating lunar sub-harmonics with multidecadal periods. It was shown that random component of regional atmospheric pressure tends to cluster at monthly intervals. The clusters are likely to be caused by the intraannual seasonal atmospheric temperature changes, which may also act as random beats in generating sub-harmonics observed in sea level changes as another mechanism. This study also affirmed that there are no statistically significant secular trends in the progression of regional atmospheric pressures, hence there was no contribution to the sea level trends during the $20^{\text {th }}$ century by the atmospheric pressure. Meanwhile, the estimated nonuniform scale factors of the inverted barometer effects suggest that the sea level atmospheric pressure will bias the sea level trends inferred from satellite altimetry measurements if their impact is accounted for as corrections without proper scaling.
\end{abstract}

Keywords: Atmospheric pressure; inverted barometer effect; sea level variations; luni-solar sub and super harmonics; tide gauges; climate change

\footnotetext{
*Corresponding Author: H. Bâki Iz: Division of Geodetic Science, School of Earth Sciences, The Ohio State University, Columbus, Ohio, USA, E-mail: h.baki.iz@gmail.com
}

\section{Introduction}

Global sea-level rise relates to the changes in air temperature associated with the increasing concentration of atmospheric $\mathrm{CO}_{2}$ (Thompson, 1986). As a result, several climate change studies evaluate sea-level atmospheric pressure $^{1}$ over time to examine how well climate models capture the observed changes and take this as an evidence for global warming (e.g., global surface temperature increases) to suggest a human influence on the global climate (Gillett et al. 2003).

In the context of sea level studies, a non-negligible component of sea level variability is the atmospheric pressure when compared to changes of steric, and eustatic origins (Ponte, 2006, Bindoff et al., 2007). Inverted barometer effects become more significant when analyzing shorter decadal records such as those from satellite altimetry (Ponte, 2006). The $\mathrm{CO}_{2}$ forcing causes changes in dry atmospheric pressure at sea level due to low-frequency changes in the atmospheric flow field and the associated shifts in air mass. An increase of water vapor in the atmosphere due to changes in the atmospheric temperature and moisture content contributes to these changes (Stammer and Hüttemann, 2008).

Robinson (1964) showed that the open ocean should respond as an inverse barometer to changes in atmospheric pressure. The sea surface is depressed $1 \mathrm{~cm}$ for each millibar $(\mathrm{mb})^{2}$ of increased atmospheric pressure so that the net bottom pressure remains constant (isostatic). Wunsch (1972) reported that at the scale of about a day to months, the sea level behaves like an inverted barometer, while for longer periods, the effects of the wind tend to dominate. Later, Trupin and Wahr (1990) demonstrated the presence of sea level response to the atmospheric pressure to be inverted barometric for periods greater than 2

\footnotetext{
1 Sea-level atmospheric pressure will be stated as atmospheric pressure for the sake of brevity. $2 \mathrm{mb}=1 \mathrm{hpa}=100 \mathrm{pa}, 1 \mathrm{pa}=1 \mathrm{kgm}^{-1} \mathrm{~s}^{-2}$
} 
months by fitting atmospheric pressure to global, monthly tide gauge data. Subsequently, Douglas (2006) reported the correlation between sea level variations of three tide gauge stations to the variations in inverted barometric effect corrections at these stations at interdecadal scales as a marginal finding in investigating fingerprints of glacial melting but stopped short of assessing their impact on long term sea level variations.

Today, the study of the impact of atmospheric pressure in modelling sea level variations is more relevant because of the need not only to estimate secular sea level trends more accurately (Piecuch et al., 2016), but also to detect an accelerating sea-level rise, which will be easier to identify with an 'IB modeled/corrected' tide gauge or satellite altimetry data. Rossiter (1967) was one of the first to correct annual sea-levels in his study of secular trends on the north-west European Shelf (see Lisitzin, 1974 and Tai, 1993 for an historical review of this topic).

On the satellite altimetry side, Wunsch (1991) investigated the sea level response to atmospheric forcing combining Geosat data with tide gauge data and filtering to retain only sea level variations at large spatial-temporal scales. He determined that some areas produce classical static inverted barometer response, but others suggest an amplified response. Removing the static inverted barometer sea level response enables investigating the remaining dynamical response to atmospheric pressure forcing in satellite altimetry (Tai, 1993). Gaspar and Ponte (1997) and Ponte and Gaspar (1999) carried out a crossover analysis of TOPEX/POSEIDON data regressed against the atmospheric pressure and determined significant correlations between various sea level signals and barometric pressure.

Meanwhile, there were observations indicating that the sea level response tends to deviate from the postulated inverted barometer response in the continental shelf regions (Hamon 1962, Wunsch et al. 1969, Chelton and Davis 1982). This study will also verify these observations and quantify the variable impact of atmospheric pressure at spatial-temporal scales to the sea level variability at globally distributed tide gauge stations.

In the following sections, first, the evidence for the presence of nonlinear changes in atmospheric pressure at the globally distributed 27 tide gauge stations is offered. In the sections that follows, the impact of nonlinearities in atmospheric pressure, as compounders, on long periodic sub-harmonic variations of luni-solar origin in sea level variations as observed in monthly tide gauge measurements is demonstrated.

\section{Atmospheric pressure}

Response of a homogeneous ocean to atmospheric pressure forcing involves a static and dynamic inverted barometer response of the sea level contributing to the sea level changes (Tai, 1993, Ponte, 2006). For the static component $\eta_{t}^{i b}$ at a given epoch $t$, the local/regional contribution is given by

$$
\eta_{t}^{i b}:=\frac{p_{t}-\bar{p}}{\rho g}
$$

where $p_{t}$ is the atmospheric pressure that varies over time. The overbar denotes a spatial average of the pressure over the global oceans, $\rho$ is surface density, and $g$ is acceleration of gravity. A simple correction is provided for a hypothetical global uniform increase of $1 \mathrm{mb}$ of the atmospheric pressure over the ocean, which would suggest a uniform sea level depression of about $1.01 \mathrm{~cm}$ according to the above inverted barometer approximation (Ponte, 1991).

The static response is forceful. It can account for more than half of the total sea level variability (Chelton and Davis, 1982, Ponte et al., 1991, Thai, 1993). The systematic contribution of atmospheric pressure to the sea level variability reduces markedly in the equatorial regions. However, this contribution never disappears but gets randomized at lower latitudes as it is shown at various tide gauges in this study.

Atmospheric pressure changes have been reported not having any significant trend (Roden, 1966) based on the analysis of sea-level pressure data at several stations along the Pacific coast of North America as also verified by this investigation. Since then, numerous studies of global mean sea level using tide gauges applied no corrections for the inverted barometer effect (Church and White, 2011, Ray and Douglas, 2011, Jevrejeva et al., 2014). Woodworth et al., (2009) stated that this correction is small on century time scales. Nevertheless, a changing atmospheric circulation implies a change in the atmospheric pressure and an associated loading effect, in principle, will contribute to regional sea level changes at low frequencies as demonstrated below. Consequently, low frequency sea level variations, if unmodeled, will bias trend estimates from the tide gauge measurements at shorter time scales, especially when the aim of the analysis is to detect sea level accelerations (Iz, 2006). Furthermore, Piecuch et al., (2016) reported that removing the effect of IB effect from yearly averaged tide gauge time series improves the uncertainties of sea level trend estimates by $10-30 \%$ and advocates the use of IB correction for the tide gauge records. 


\section{Regional atmospheric pressure data at globally distributed tide gauge stations}

Twenty-seven tide gauge locations shown on Fig. 1 with long records were selected in order verify the outcomes of the earlier studies, using updated atmospheric pressure data, and to further gain insight about their properties. Most of the tide gauge stations at these locations span tide gauge observations over a century and were scrutinized repeatedly over the last decade by Iz, 2006-2016.

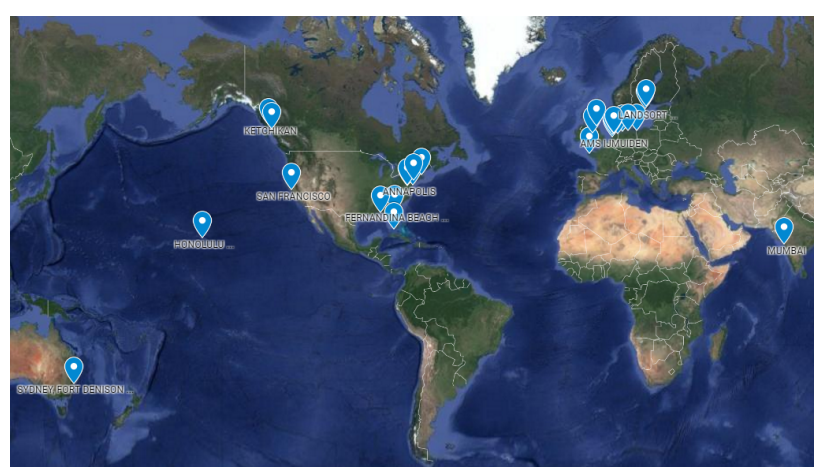

Figure 1: The locations of the 27 tide gauge stations used in this study are indicated with drops (Google map, 2016).

Figure 2 displays regional atmospheric pressure variations surrounding these tide gauge stations. The data were download from the Hadley Center's historical mean sea level pressure repository. The atmospheric pressure series, HadSLP2, is based on numerous terrestrial and marine data compilations on a $5^{\circ}$ latitude by $5^{\circ}$ longitude grid covering the period from 1850 to 2004 (Allan and Ansell, 2006). Despite the large areal coverage, the regional data are representative of the atmospheric pressure effect at the corresponding local tide gauge stations because of the high areal coherence of sea surface pressure up to $1200 \mathrm{~km}$ (Roden, 1960).

In Figure 2, the regional atmospheric pressure series are plotted with a common vertical scale to disclose average differences visually at different locations. Some of the records are identical because of the proximity of the tide gauge stations to each other. The averages vary between 1003.8-1020.4 mb with a range of $0.1-0.2 \mathrm{mb}$ for the standard errors of their mean values, while exhibiting strong dependency on the latitude as reported by earlier investigations (Ponte, 2006). On the plots, the connecting lines were not used to reveal some of the stratifica- tion/clustering in the series, a topic to be examined in the following section.

\section{Properties of regional atmospheric pressure at tide gauge stations}

In general, the atmospheric pressure series exhibit one of the properties of the two examples presented in Fig. 3. These examples are intended to detail the analysis carried out at the selected 27 globally distributed tide gauge stations. Atmospheric pressure series surrounding Key West, USA, and New York, USA regions span through 1850-2005. Averaged 1860 monthly values were extracted for each location from the HadSLP2 data set (Allan and Ansell, 2006). The progression of the atmospheric pressure series is dominantly random in the case of Key West, as revealed by its slightly skewed right tailed histogram with an almost flat white noise spectrum. They can also be multimodal as in the case of New York atmospheric pressure series (Fig. 3). Both atmospheric pressure series have a pronounced annual component evident in their power spectra and in their correlograms. Overall, the amplitude of the yearly variations attenuates for stations closer to the equator but never disappears.

Solutions using a preliminary ${ }^{3}$ model with a deterministic trend and the sine and cosine components of annual periodicities superimposed with an assumed homoscedastic noise were carried out for both time series to explore their systematic and random properties. The estimates show that the Key West atmospheric pressure series have a statistically significant ${ }^{4}$ trend $-0.012 \pm 0.002 \mathrm{mb} / \mathrm{yr}$ $(p<0.00)$, which translates into a decreasing secular trend in sea level of about $-0.12 \pm 0.02 \mathrm{~mm} / \mathrm{yr}$, with an adjusted $\mathrm{R}^{2}$ value of $16.8 \%$. Despite the predominantly noisy nature of the fit, the solution passes the F-test ${ }^{5}(\mathrm{p}<0.00)$. The trend estimate is also significant in the sense that the inverse barometric contribution to the sea level trends can be as large as the contributions from halosteric or thermosteric origin at some localities. The atmospheric pressure trend for the New York region is $-0.002 \pm 0.001 \mathrm{mb} / \mathrm{yr}$,

3 Note that both solutions' statistics presented here are preliminary. The statistics will be different once the models are finalized (see Table 1 for the final results).

$4 p=0.05$ is adopted as a borderline for the statistical significance of the tests throughout this study.

5 i.e. the model still has a statistically significant predictive power. 


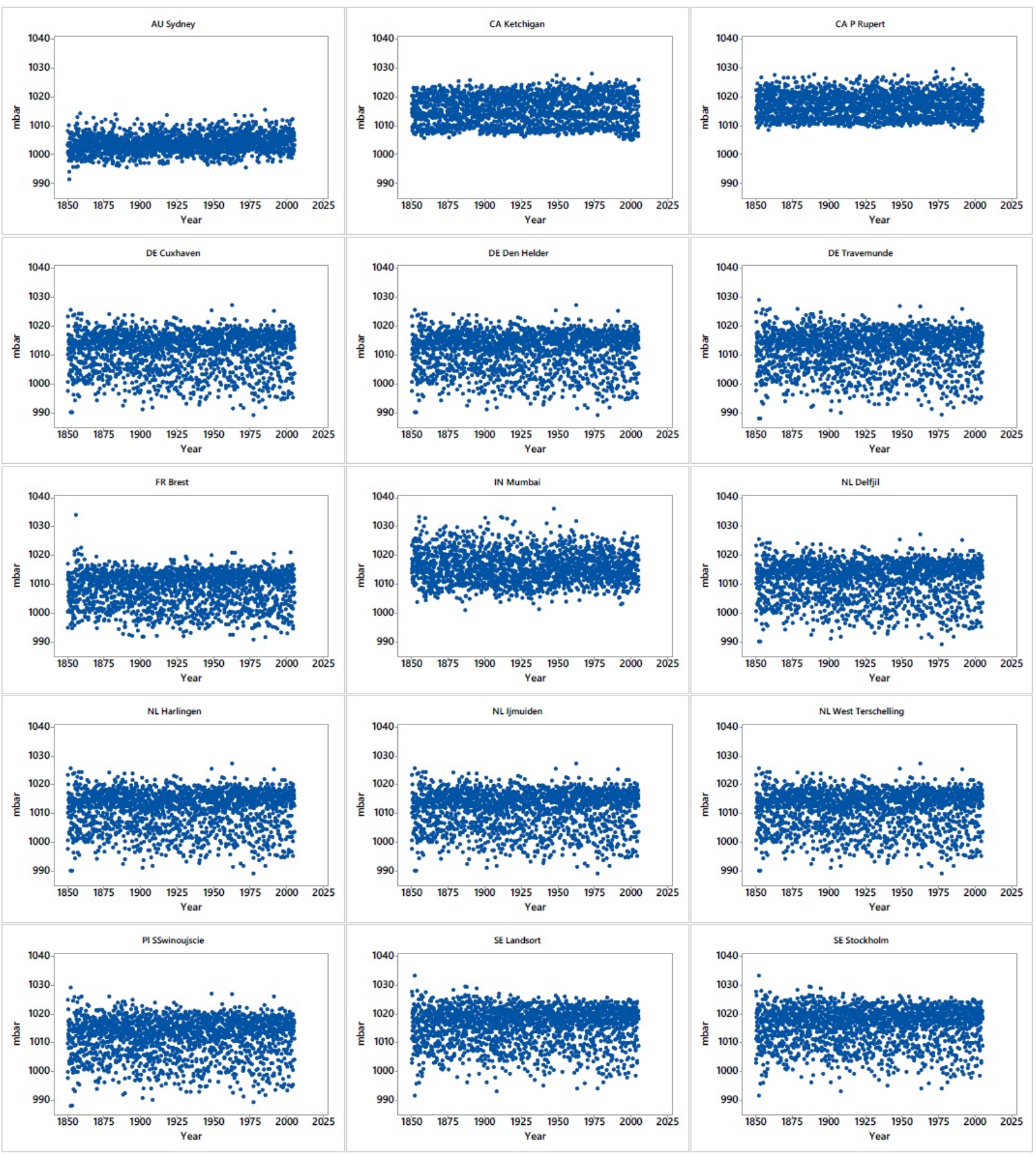

Figure 2: Regional atmospheric pressure time series at 27 globally distributed tide gauge stations with long records. Some of the records are identical because of the proximity of the tide gauge stations to each other.

which is equivalent to $-0.02 \pm 0.01 \mathrm{~mm} / \mathrm{yr}$ sea level trend. The model explains $96 \%$ of the variations in the atmospheric pressure by the yearly variations. Nonetheless, the trend is not an important contributor to the sea level trend at the New York tide gauge station despite being statistically significant $(p<0.02)$. On the other hand, the amplitude of the annual periodicity in pressure variation at the
New York station is $12.71 \pm 0.06 \mathrm{mb}$, which is markedly large in contrast to the estimated amplitude of the yearly periodic changes experienced at the Key West TG station, which is $2.60 \pm 0.14 \mathrm{mb}$.

The residuals of these preliminary solutions however revealed unmodeled atmospheric pressure variations at the sea level, which biased the sea level related parameter 


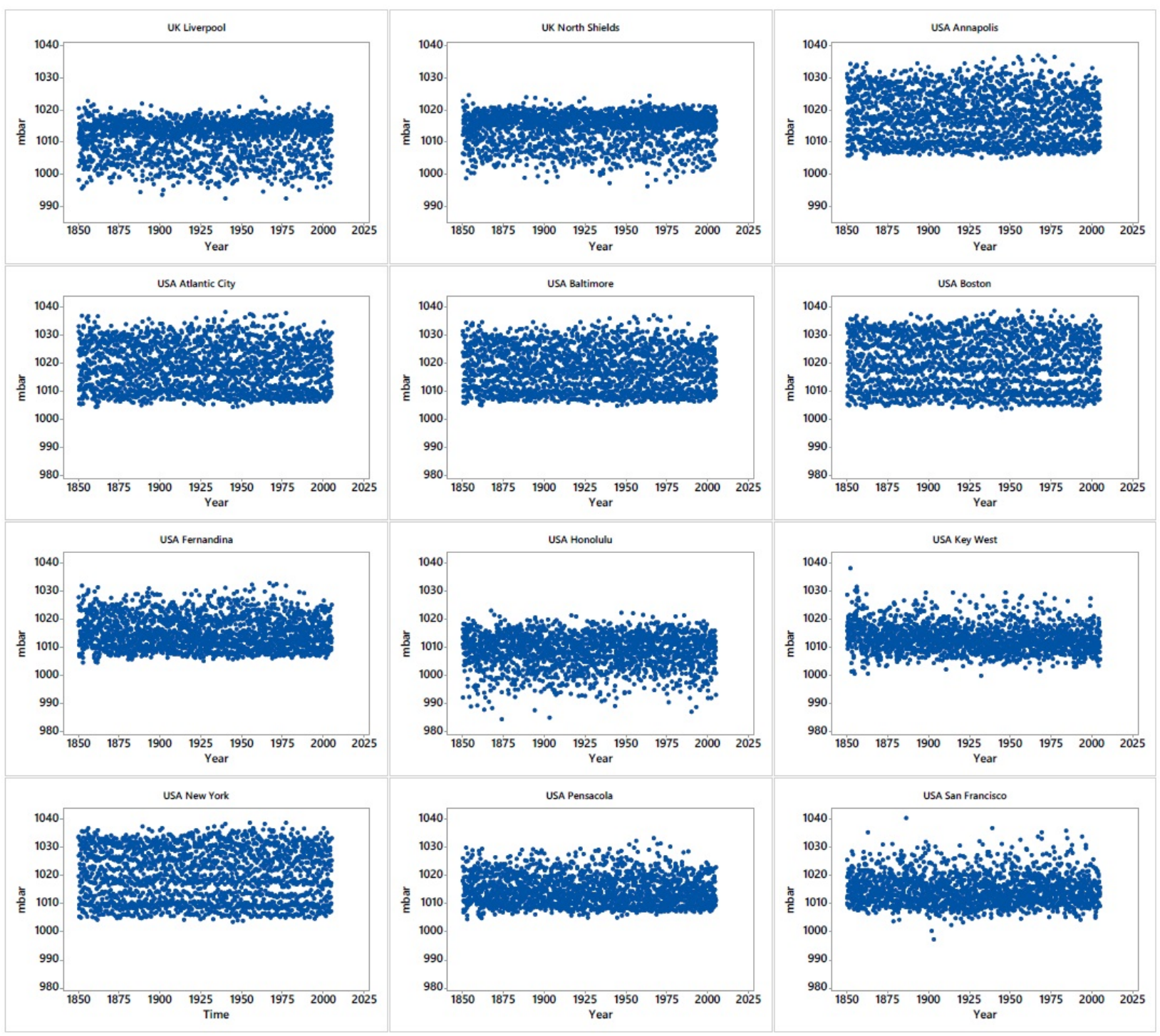

Figure 2: (Continued)

estimates as it will be shown through the following solutions. The residual and the histogram plots of atmospheric pressure time series shown in Fig. 4 for the two sample solutions suggest normally distributed residuals for both regions. Nonetheless, when the residuals plotted against their adjusted (fitted) atmospheric pressure values, they exhibit heteroscedasticity in Key West observations (increasing variability in the residuals). More importantly, a non-linear unmodeled effect (a cubic with a negative sign) is revealed. The plot for the New York time series residuals also exhibit an atypical clustering at monthly intervals.

Solution statistics were also affected by the unmodeled non-linear effects (Table 1). The clusters of residuals for the New York model solution are ordered monthly with increasing dispersion as in the case of Key West residual series. Monthly clusters suggest that, in addition to the periodic annual variation in atmospheric pressure, there are unexplained changes, as if they are random beats occurring at monthly intervals.

Although, the residual clustering seems to disappear for the Key West atmospheric pressure series, a close examination reveals that monthly signatures persist but weaker in the presence of more dispersed random variations. In any case, clustering and nonlinearities are all present surrounding the 27 tide gauge stations' atmospheric pressure series as revealed by the plots in Fig. 5 . The clusters are not caused by high frequency sub annual pressure variations. They are also not transient.

The following kinematic model accommodates the effect of unmodeled nonlinearities in the residuals of the 

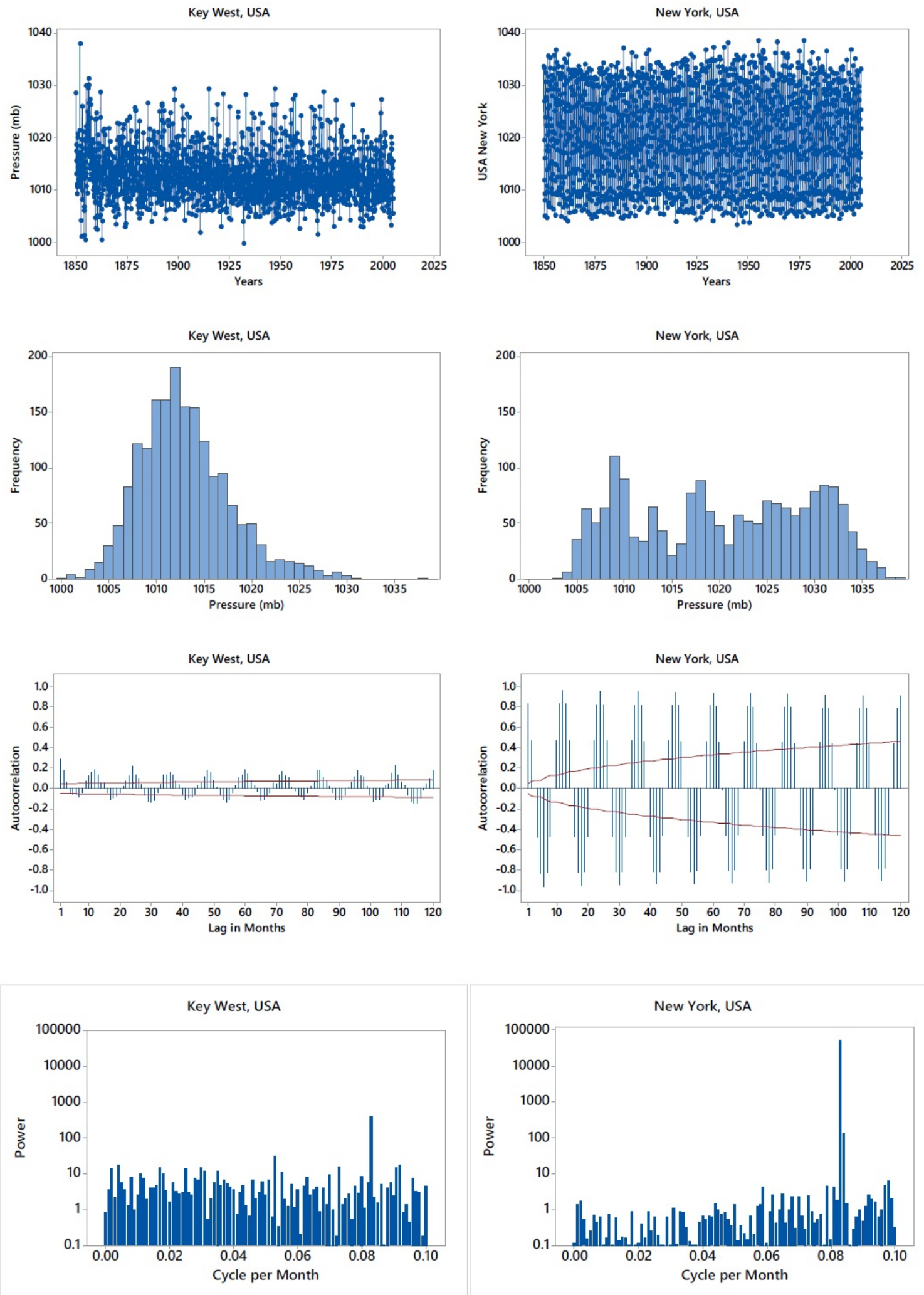

Figure 3: Atmospheric Pressure time series at Key West, USA and New York, USA tide gauge stations. 

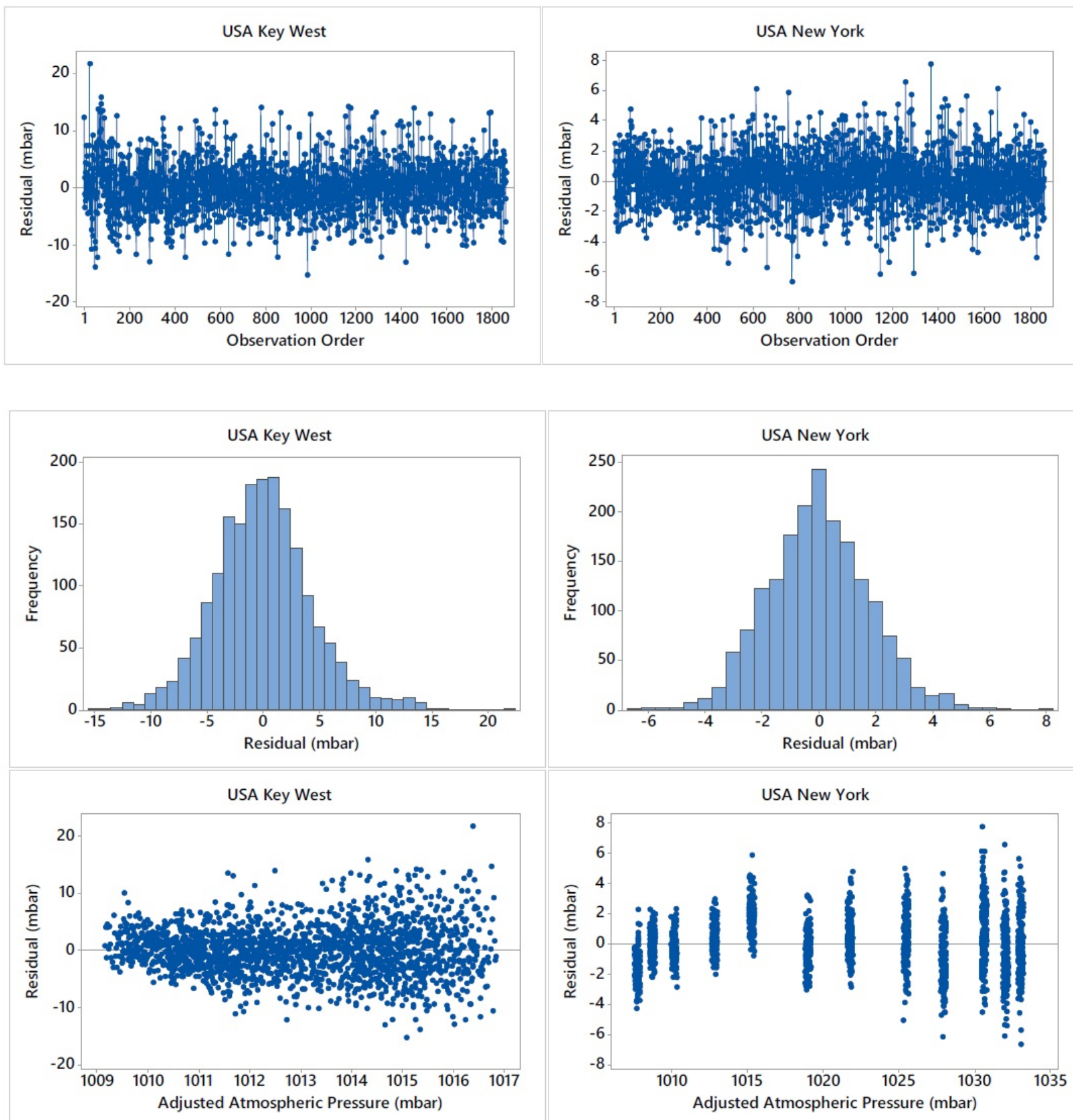

Figure 4: Residual atmospheric pressure plots at Key West and New York tide gauge stations in mb followed by their histograms. Third row plots are the residuals plotted agains their adjusted values (fitted values).

preliminary solutions for all 27 atmospheric pressure series. The model consists of an acceleration and change in the acceleration parameter, accompanied by a secular trend, and parameters for the annual and semiannual periodic changes in the atmospheric pressure together with random effects,

$p_{t}=p_{t_{0}}+\dot{p}\left(t-t_{0}\right)+\frac{\ddot{p}}{2}\left(t-t_{0}\right)^{2}+\frac{\dddot{p}}{6}\left(t-t_{0}\right)^{3}$

$$
\begin{aligned}
& +\alpha_{A} \cos \left(\frac{2 \pi}{P_{A}}\right)\left(t-t_{0}\right)+\gamma_{A} \sin \left(\frac{2 \pi}{P_{A}}\right)\left(t-t_{0}\right) \\
& +\alpha_{S A} \cos \left(\frac{2 \pi}{P_{S A}}\right)\left(t-t_{0}\right)+\gamma_{S A} \sin \left(\frac{2 \pi}{P_{S A}}\right)\left(t-t_{0}\right)+\epsilon_{t}
\end{aligned}
$$

In this representation, an average monthly regional atmospheric pressure at an epoch $t$ is denoted by $p_{t}$. The intercept $p_{t_{0}}$ is the atmospheric pressure defined at the reference epoch which is selected to be the mid-epoch of 

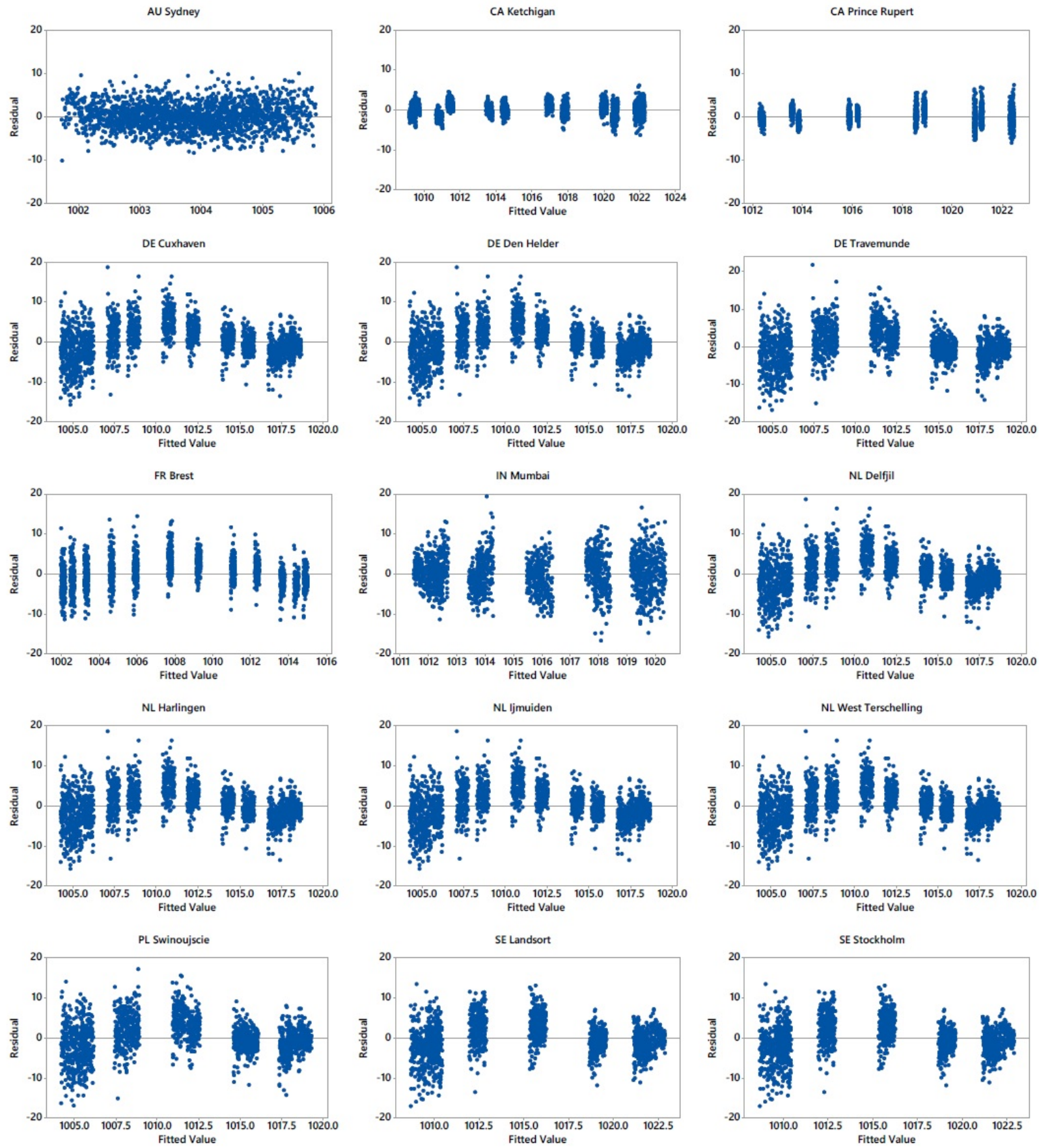

Figure 5: Residual atmospheric variations at all 27 globally distributed tide gauge stations were calculated using a preliminary model with a deterministic trend, and the sine and cosine components of annual periodicities superimposed with a homoscedastic noise. Note that some of the plots are identical because some stations share the same regional atmospheric pressure data.

each series. The constant rate of change (velocity/trend) in the atmospheric pressure is denoted by $\dot{p}$, and, $\ddot{p}$ and $\dddot{p}$ are the parameters for the acceleration and change in the acceleration. $P_{A}, P_{S A}$ represent the annual and semiannual periodic changes in the atmospheric pressure series. Each period introduces two parameters, $\alpha, \gamma$ for the sine and cosine components from which the amplitudes and the phase angles of the periodic terms are calculated. In total, the extended kinematic model includes 8 unknown parameters to be estimated. The random variable denoted by $\epsilon_{t} \sim\left(0, \sigma_{\epsilon}^{2}\right)$ represents the random errors that 

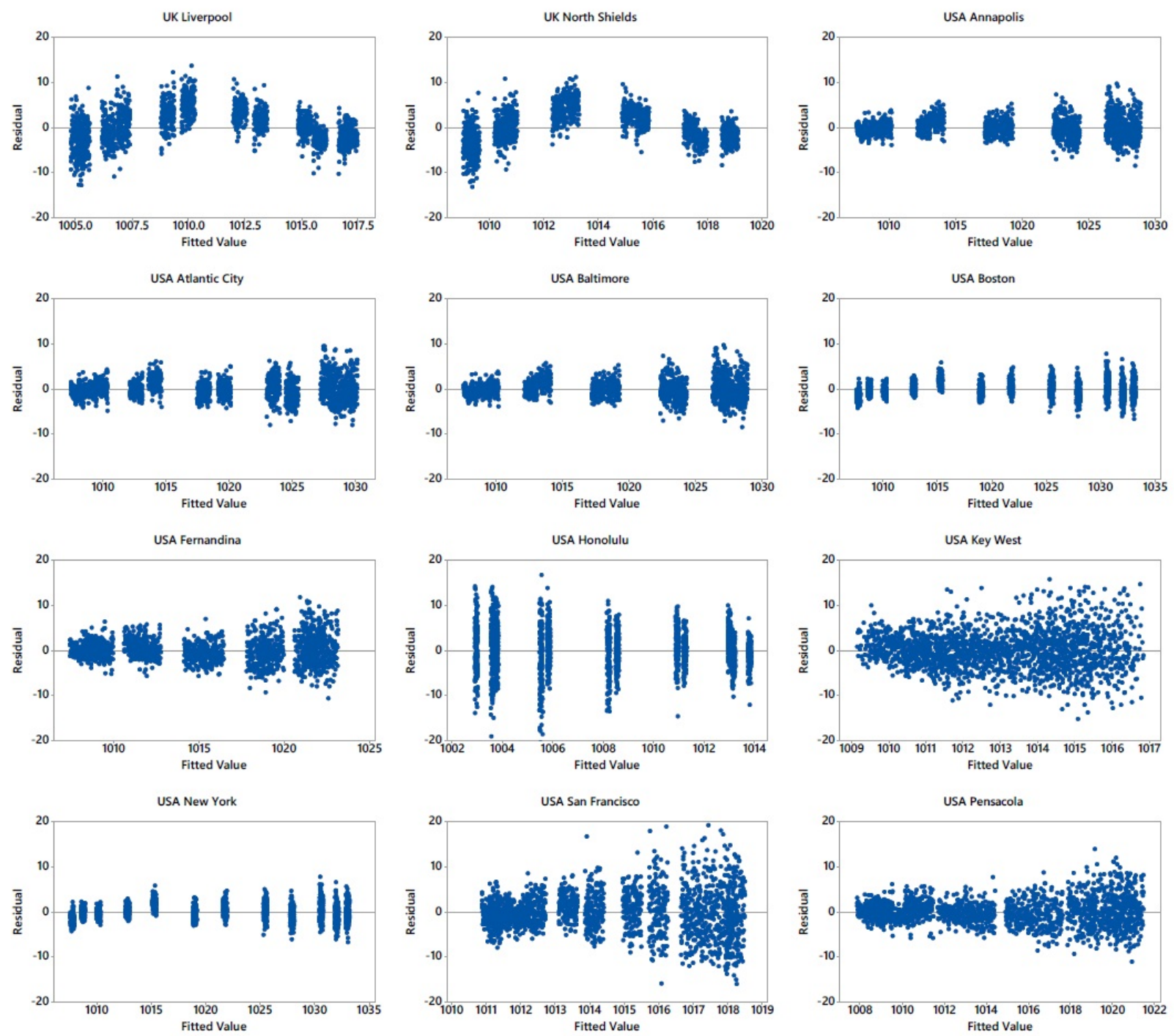

Figure 5: (Continued)

are assumed to be uncorrelated ${ }^{6}$ with zero expected value and homoscedastic in nature since the effect of the nonhomogeneity did not impact the solution statistics significantly.

Table 1 lists all the solution statistics calculated using the above model. All the results conform with the earlier findings. Stations along the eastern United States are subject to periodic changes with larger amplitudes as compared to the others. Stations closer to the equator are also exposed to yearly periodic variations but with smaller amplitudes. Large adjusted $\mathrm{R}^{2}$ values show that the models explain most of the variations in atmospheric pressure observed at the sea level at the corresponding stations. For those stations closer to the equator, the amplitudes of the annual and semiannual changes are considerably smaller and overwhelmed by random excursions. Stations in Europe experience similar regional variations because of their proximities to each other7.

Except for the two tide gauge stations in Canada, and Fernandina and Honolulu, USA, there are no statistically significant secular changes (trends) in atmospheric pressure at the remaining 23 tide gauge stations. Only at 6 stations atmospheric pressure accelerate/decelerate, reflecting no dominant global behavior. Among them Mum-
6 Once the annual periodic variations are removed from the atmospheric series, the residuals do not exhibit any autocorrelation.
7 Most of the regional atmospheric data overlap at stations located in Nordic countries. 
bai, India has the largest acceleration $0.00032 \mathrm{mb} / \mathrm{yr}^{2}$, an equivalent inverted barometer contribution to the sea level rise acceleration of about $0.0032 \mathrm{~mm} / \mathrm{yr}^{2}$, which could be an important contributor to the sea level changes at this tide gauge location if it is sustained over a long period of time.

The third order effect, a cubic, (change in the acceleration in the physical context) is prevalent at the eastern North Atlantic Coast of the United Stated with an increasing acceleration followed by a deceleration. These non-linear atmospheric variations are visually evident in the preliminary residual plots (Fig. 5). The nonlinear models explain also most of the atmospheric pressure variabilities at Annapolis, Atlantic City, Baltimore, Boston, USA tide gauge stations with Adjusted $\mathrm{R}^{2}$ values exceeding $92 \%$. Moreover, in addition to being statistically significant, they contribute markedly to the longterm sea level changes experienced at these stations. For instance, a change in the atmospheric pressure of about $-0.00001 \mathrm{mb} / \mathrm{yr}^{3}$ at one of these stations, if not accounted for, will bias the sea level trend approximately $1 \mathrm{~mm} / \mathrm{yr}$ for a 50-year tide gauge time series ${ }^{8}$.

In addition, a lurking impact of atmospheric pressure changes can be attributed to the monthly clusters displayed in the preliminary residual plots of Fig. 5. These monthly unexplained imprints are less clustered but still persistent even after the periodic, linear and non-linear effects are removed.

The repeated spectral analyses of the residuals for all 27 atmospheric pressure series after the nonlinear variations were removed revealed no statistically significant frequencies in their residuals. Nonetheless, the residuals still exhibit multi-modal changes clustered at certain pressure magnitudes repeating within the same month of every year with random excursions with varying variances (suggesting non-stationarity in variance). These repetitive behaviors can be interpreted as a realization of a broadband random beat mechanism proposed by Keeling and Whorf (1997), Treloar (2002) and debated by Munk et al. (2006) in the context of climate variability as another potential compounding source of low frequency changes in the ocean interacting with lunisolar periodicities in sea level changes and generating sub and super harmonics. The presence of their proposed compounding mechanism was demonstrated by Iz, (2014) using meta-analysis in generating sea level changes of sub and super harmonics of luni-solar origin. In this interaction, atmospheric pressure is now one of the possible contributors to the long periodic sea level variability in addition to the thermosteric effects (Iz, 2016a). This conjecture will be investigated in the next section.

Table 1: The estimates for the atmospheric pressure model parameters namely; trends, accelerations, change in the accelerations and the amplitudes of the periodicities calculated from their estimated components, and their statistics. The amplitudes of the periodicities are in $\mathrm{mb}$, which are followed by their standard deviations. Mean square error of the residuals (a posteriori variance of unit weight) is denoted by $\hat{\sigma}^{2}$. Atmospheric pressure velocity estimates (trends) are in $\mathrm{mb} / \mathrm{yr}$. Statistically significant estimates are highlighted.

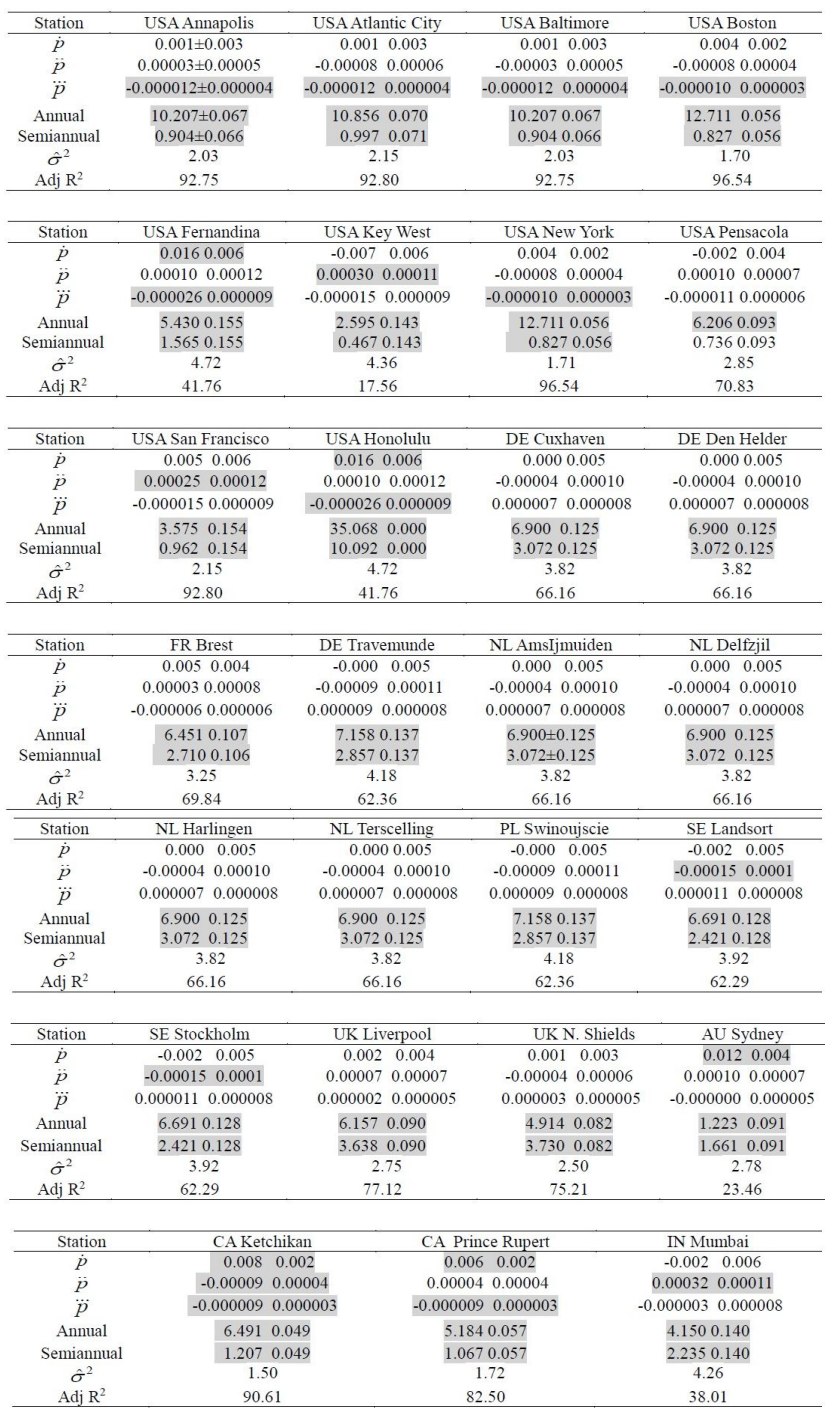

$8-0.00001 \mathrm{mb} / \mathrm{yr}^{3}$ is equivalent to a sea level rise of $0.0001 \mathrm{~mm} / \mathrm{yr}^{3}$, which cumulatively increases the sea level by $62.5 \mathrm{~mm}$ during a 50year time span. 


\section{Contribution of atmospheric pressure to the sea level variations at selected tide gauge stations}

At any fixed location, the sea level record is a function of time, involving periodic components as well as continuous random fluctuations. The periodic motion is mostly due to the gravitational effects of the sun-earth-moon system as well as because of solar radiation upon the atmosphere and the ocean as discussed before. Sometimes the random fluctuations are of meteorological origin and reflect the effect of 'weather' upon the sea surface but reflect also the inverse barometric effect of atmospheric pressure at sea level.

Iz (2014), (2015) has demonstrated that sea level variation experienced at a tide gauge station can be effectively reconstructed using harmonic models as follows. The model consists of a datum parameter, kinematic parameters of a secular sea level trend and acceleration, sub and super harmonics of luni-solar origin generated by the compounding of external forcings by the moon and the sun, and natural variations. This model will now be augmented (the augmented model) by adding another parameter ${ }^{9}$ to overtly account for the atmospheric pressure as the inverted barometer effect at sea level in the model. Systematic effects are superimposed with autocorrelated random excursions.

$$
\begin{aligned}
h_{t}= & h_{t_{0}}+\dot{h}\left(t-t_{0}\right) \\
& +\sum_{h=1}^{16}\left[\alpha_{h} \cos \left(\frac{2 \pi}{P_{h}}\right)\left(t-t_{0}\right)+\gamma_{h} \sin \left(\frac{2 \pi}{P_{h}}\right)\left(t-t_{0}\right)\right] \\
& +s \frac{p_{t}-\bar{p}}{\rho g}+\epsilon_{t}
\end{aligned}
$$

where,

$$
\epsilon_{t}=\rho \epsilon_{t-1}+v_{t} \quad 0 \leq \rho<1
$$

In this representation, a tide gauge measurement at an epoch $t$ is denoted by $h_{t}$. The intercept $h_{0}$ is the height of the sea level at the reference epoch $t_{0}$ defined to be the middle epoch of the series. The constant rate of change (velocity/trend) in the sea level is denoted by $\dot{h}$. The periodicities $\left(P_{h}, h=1, \ldots, m\right)$ consist of eleven sub and super harmonics of node tides and those attributed to the solar radiation shown on Table 1. Each period introduces

9 Dynamic and static atmospheric effects are not differentiated. two parameters, $\alpha_{h}, \gamma_{h}$ for the sine and cosine components from which the amplitudes and the phase angles of the periodic terms are determined. In total, the extended model includes 35 unknown parameters common to all tide gauge stations in addition to a scale parameter, $s$, for the inverted barometers effect given by Eq. (2).

Table 2: Compounded periodicities (yr) of Luni-Solar origin incorporated into the model.

\begin{tabular}{lccccc}
\hline Nodal & Nodal & Nodal & Solar & Annual & Chandler \\
\hline 74.5 & 18.6 & 3.7 & 11.1 & 1.00 & $429.5 / 365.4$ \\
55.8 & 9.3 & 3.1 & 22.2 & 0.50 & \\
37.2 & 6.2 & 2.6 & & & \\
& 4.7 & 2.3 & & & \\
\hline
\end{tabular}

The random variable denoted by $\epsilon_{t} \sim\left(0, \sigma_{\epsilon}^{2}\right)$ represents the autocorrelated random errors - determined to be a first order autoregressive process with variance $\sigma_{\epsilon}^{2}$ (Iz, 2012) with zero expected value. The error at an epoch $t$ is related to the error of the previous epoch through Eq. (4). The unknown first order autocorrelation coefficient $\rho$ was shown to be positive and needs to be estimated in all tide gauge measurements (ibid). The other random error componenthas an expected value of zero and it is independently distributed, $u_{t} \sim\left(0, \sigma_{u}^{2}\right)$ i.e. , where $\sigma_{u}^{2}$ is the variance of the white noise.

It was shown that the correlation coefficients for the autocorrelations are mostly within the range $0.3-0.4$, not negligible, yet having no impact on the estimated parameters (Iz et al., 2012, 2013). Nonetheless, unaccounted positive serial correlations bias the solution statistics, such as the variance of the estimated parameters, by underestimating, and overstating the adjusted $R^{2}$ statistics ${ }^{10}$ and consequently induce false positives in null-hypothesis testing of the model parameters, i.e. statistical significance of the estimated parameters, and the model performance (Neter et al., 1996).

Now, note that in the above model some of the explanatory variables are duplicated. For instance, harmonic portion of the model includes representation for the annual and semi-annual variations, which are also embedded in the pressure data as it was demonstrated in the previous section. Given the fact that luni-solar sub and super harmonics are realized because of the compounding

10 Adjusted $R^{2}$ statistics refer to the coefficient of determination; percentage of variation in the data explained by the model adjusted by the number of model parameters. 
of forced external or natural sea level variations, it is likely that nonlinear changes in atmospheric pressure (or beats due to clustering) could be the compounding agent. If this is the case, a comparison of two least square solutions, one without the atmospheric pressure parameter and another with the atmospheric pressure parameter, will be revealing. The estimates from both model solutions will be different if the atmospheric pressure data and the harmonic parameters share the same information. In extreme cases, the variance inflation factors, VIFs ${ }^{11}$ for the estimates in the augmented model solutions will disclose the dependency of each parameter to the atmospheric variations at each tide gauge stations.

Table 3 is the product of these two solutions for all 27 tide gauge stations' sea level data. The results reflect the effect of the statistically significant variations in atmospheric pressure detected in the previous section and the sea level variations. Annual and semiannual changes in atmospheric pressure data explain effectively the corresponding annual and semi-annual periodicities in the augmented model.

The variance inflation factors, VIFs, reveal the existence of shared information between the other harmonic model parameters and the IB representation. The effect of statistically significant non-linear changes in the atmospheric pressure (quadratics and cubics) turned out to be potential compounders generating subharmonics of the lunar nodal forcing with period $18.6 \mathrm{yr}$, which are generating these low frequency sea level variations (subharmonics). Changes in the estimated amplitudes of the subharmonics, which are highlighted on the Table 3 provide further evidence for the role of the atmospheric pressure. Note that the changes in the estimated amplitudes calculated using both models cannot be assessed statistically since they are based on the same tide gauge time series data, i.e. they are not independent. Therefore, using a judgment call, changes exceeding $4 \mathrm{~mm}$ in amplitude at each station's harmonics were deemed to be significant. A lower threshold will find additional parameters to be included in this list. Overall, contribution of atmospheric pressure is pronounced along the tide gauge stations located along eastern coast of USA and at the two Canadian tide gauge stations and it exists sporadically at the European tide gauge locations.

Both models are equivalent as far as their explanatory powers are concerned. For instance, additional statistics for the New York Tide gauge station model solutions are

11 VIFs are calculated by regressing one parameter to the remaining model parameters (see the appendix of Iz, 2014).
2.82 and 2.86 for the a posteriori variance of unit weight ${ }^{12}$ for the harmonic and augmented model respectively. Both model solutions explain 59.21 and 55.19 percent (Adjusted $\mathrm{R}^{2}$ values) of variations in the sea level tide gauge data. Similarly, Durbin-Watson statistics are 1.95 and 2.10 indicative of purely random properties of the residuals from both models. There are however, differences, such as at the Key West station where the effect of atmospheric pressure is irregular, and the magnitudes of the annual and semiannual variations are small.

Another inference can be made by comparing the magnitude of the estimated scale factor, $s$, of the inverted barometer effect listed on the same table (IB). Under ideal circumstances, when the globally averaged atmospheric pressure is used in model solutions, a hypothetical global uniform increase of $1 \mathrm{mb}$ of the atmospheric pressure over the oceans is expected to correspond to a uniform sea level depression of about $1.01 \mathrm{~cm}$. Thereby, the expected value of the scale factor is equal to 1 , or -1 if the atmospheric pressure decreases. Because the globally averaged atmospheric pressure is unknown, a standard atmosphere of $1013.25 \mathrm{mb}$ was used throughout the augmented model solutions. Therefore, the scale factor estimate will be different from its expected value of 1 or -1 . However, except for the magnitude of the scale factor, $s$, tabulated in Table 3, different average atmospheric pressure values will have no effect on the other estimated parameters and on the solution statistics (least squares solutions are invariant with respect to the shifts in independent variables).

Observe in Table 3 that the scale estimates are markedly different as a function of tide gauge location, and consequently, will be a considerable source of bias if IB effects for instance, are applied to satellite altimetry observations as corrections without their scale factors, which seem to be the general practice (Kuo, 2017).

\section{Conclusion}

The study provides additional information about the impact of atmospheric pressure on sea level variations. Statistically significant nonlinearities were found in the regional atmospheric pressure series, which impacted longterm sea level changes depending on the geographical region. Close to the equator, air pressure variations are dominantly random and the regularity in sea level atmospheric pressure depends mainly on the latitude and per-

$\overline{12}$ i.e. root mean square error of the residuals in $\mathrm{mm}$. 
Table 3: The estimates for the two model parameters (trends and the amplitudes of the periodicities calculated from their estimated components) and their statistics for all the tide gauge stations are listed. The amplitudes of the periodicities are in mm, which are followed by their standard deviations. Station velocity estimates (trends) are in $\mathrm{mm} / \mathrm{yr}$. The first set of estimates were calculated without the parametrization of the IB effect in the model. The highlighted amplitudes and the trend estimates are all impacted by the inclusion of the atmospheric pressure in the model if the amplitude changes were larger than $4 \mathrm{~mm}$. No estimates are available for the blank cells. Because of their high VIFs, the corresponding periodicities were not included in the models.

\begin{tabular}{|c|c|c|c|c|c|c|c|c|c|c|c|c|c|c|c|c|}
\hline \multirow[t]{2}{*}{$\begin{array}{l}\text { Station } \\
\text { Length }\end{array}$} & \multicolumn{4}{|c|}{$\begin{array}{c}\text { Annapolis } \\
81 \mathrm{yr}\end{array}$} & \multicolumn{4}{|c|}{$\begin{array}{c}\text { Atlantic City } \\
98 \mathrm{yr}\end{array}$} & \multicolumn{4}{|c|}{$\begin{array}{c}\text { Baltimore } \\
107 \mathrm{yr}\end{array}$} & \multicolumn{4}{|c|}{$\begin{array}{c}\text { Boston } \\
89 \mathrm{yr}\end{array}$} \\
\hline & $E$ & $\sigma$ & $E$ & $\sigma$ & $E$ & $\sigma$ & $E$ & $\sigma$ & E & $\sigma$ & $E$ & $\sigma$ & $E$ & $\sigma$ & $E$ & \\
\hline IB $(s)$ & NA & NA & 0.83 & - & NA & $\mathrm{VA}$ & - & - & $\mathrm{NA}$ & NA & 0.96 & & $\mathrm{NA}$ & 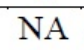 & -0.1 & 0. \\
\hline & 3.64 & & 60 & & & & & & & 11 & & & 56 & 07 & 254 & \\
\hline H & VIF & VIF & VIF & & 1 & 1.02 & V] & & 71 & 53 & $1 \mathrm{IF}$ & & 1 & VIF & VIF & VIF \\
\hline A55 & 58.86 & 19.78 & 22.88 & 60 & 50. & 12.99 & 12.29 & & 4 & 4.16 & 18.07 &  & 2.54 & $4 .($ & 26.9 & \\
\hline $\mathrm{A} 31$ & 20.76 & 7.04 & 15.36 & 75 & 1 & 5. & 6. & & 8.46 & 3.97 & 97 & & 2 & 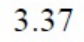 & & \\
\hline A22 & 6.07 & 21 & 6.09 & & 10 & 53 & 7.8 & & 4.8 & .92 & & & o & 2.7 & 4. & \\
\hline & 3.5 & & 45 & & & & 12. & & & .77 & & & 8 & 2.58 & 4. & \\
\hline & & & & & & & & & & 71 & & & & & & \\
\hline & & & 94 & & & & & & & .68 & & & & 2.47 & & \\
\hline & .40 & & & & & & & & & 66 & & & & 2.3 & & \\
\hline & & & 0.6 & & & & & & & 2.64 & & & & 2. & & \\
\hline & & & & & & & & & & 2. & & & & 2. & & \\
\hline & & & & & & & 4.8 & & & 2.63 & & & .33 & 2.37 & 4. & 2 \\
\hline & & & 7.6 & & & 3.06 & 6.8 & & 7.61 & 2.64 & 6.57 & & 2. & 2.35 & 3.54 & 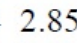 \\
\hline & & & 2.35 & & & 3.06 & 2. & & 3.0 & 2.63 & 3.72 & 3. & 5.08 & 2.34 & 5.75 & 2. \\
\hline & 1064 & & 10.0 & & & & & & & 2. & 4.15 & & 11.76 & 2. & 10.46 & 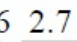 \\
\hline & & & VIF & & & & V] & & & 25 & & & & $2.2^{2}$ & VIF & VI \\
\hline & & & VIF & & & & VIF & VIF & & 30 & VIF & VIF & 0.2 & 2.06 & VIF & VIF \\
\hline
\end{tabular}

haps on the coastal geometry in parallel to the earlier studies (Ponte et al., 1991, Ponte and Gaspar, 1999, Ponte, 2006). At all tide gauge stations, most of the annual and semiannual sea level variations can be explained by regional/local atmospheric forcing as an inverted barometric effect.

The relationship between the regional atmospheric forcing and the sea level variations in this study further indicates that the origin of some of the low frequency changes (subharmonics) experienced at tide gauges can be attributed to the changes in the upper ocean layer induced by the atmospheric pressure at sea level compounded by external forcing of lunar origin.

Monthly clustering of the regional atmospheric pressure is due to the intra-annual seasonal atmospheric temperature changes and can also act as random beats in generating sub-harmonics observed in sea level changes. The random beats at some of the tide gauge stations closer to the equator has also the propensity of an increasing dispersion during the $20^{\text {th }}$ century (Fig. 5), a finding that needs to be investigated.

Meanwhile, because a warming of the upper layer of ocean surface and increase in sea surface temperature may also lower the air pressure above the warming area, further studies will be needed to investigate the interplay between atmospheric pressure and thermosteric effects experienced at tide gauge stations. As shown by Iz, (2016a) thermosteric effects mainly sea surface temperature variations do also play a role in the genesis of low frequency sea level changes. A correlational model, which will include sea surface temperature variations and atmospheric pressure together with additional periodicities of astronomical origin (Treloar, 2002), can be used to distinguish their contributions to sea level variations.

This study has also affirmed that the regional atmospheric pressure does not contribute to the sea level trends estimated from century long tide gauge records. However, the effect of unmodeled low frequency changes on shorter sea level time series, such as those from satellite altimetry, are demonstrated to be significant (Iz, 2006-2016) and atmospheric pressure is now understood to be one of the potential confounders that can bias sea level trend estimates using shorter satellite altimetry as also reported by Ponte, (2006).

Recently, Piecuch et al., (2016) reported that removing the effect of IB effect from the yearly averaged tide gauge 
Table 3: (Continued)

\begin{tabular}{|c|c|c|c|c|c|c|c|c|c|c|c|c|c|c|c|c|}
\hline \multirow[t]{2}{*}{$\begin{array}{l}\text { Station } \\
\text { Length }\end{array}$} & \multicolumn{4}{|c|}{$\begin{array}{c}\text { Fernandina } \\
112 \mathrm{yr}\end{array}$} & \multicolumn{4}{|c|}{$\begin{array}{c}\text { Key West } \\
97 \mathrm{yr}\end{array}$} & \multicolumn{4}{|c|}{$\begin{array}{c}\text { New York } \\
154 \mathrm{yr}\end{array}$} & \multicolumn{4}{|c|}{$\begin{array}{c}\text { Pensacola } \\
87 \mathrm{yr}\end{array}$} \\
\hline & E & $\sigma$ & E & $\sigma$ & E & $\sigma$ & E & $\sigma$ & E & $\sigma$ & E & $\sigma$ & E & $\sigma$ & E & $\sigma$ \\
\hline IB $(s)$ & NA & NA & -0.49 & 0.07 & NA & NA & -0.19 & 0.04 & NA & NA & -0.53 & 0.02 & NA & NA & -0.60 & \\
\hline Velocity & 2.27 & 0.19 & 2.21 & 0.35 & 2.21 & 0.24 & 2.15 & 17 & 85 & 0.06 & $\begin{array}{ll}6 & 2.82\end{array}$ & 0.08 & 2.21 & 0.11 & 2.13 & \\
\hline A74.5 & 16.79 & 7.63 & VIF & VIF & 11.72 & 5.36 & VIF & IF & 8.27 & $3.5 \mathrm{c}$ & $\begin{array}{ll}0 & 8.19\end{array}$ & & VIF & IF & VIF & \\
\hline A55.8 & 24.94 & 8.71 & 16.17 & 14.24 & 17.87 & 8.51 & 7.2 & 6.89 & $9 \quad 11.1$ & 3.46 & $\begin{array}{ll}6 & 11.37\end{array}$ & $7 \quad 4.32$ & 21.30 & 7.56 & 18.34 & \\
\hline A37.2 & 8.86 & 6.87 & 12.90 & .76 & 18.21 & 4.31 & 15.78 & 78 & 1.36 & 3.11 & 11.66 & 3.39 & 23.14 & 5.49 & 21.61 & ( \\
\hline A 22.0 & 18.97 & 5.14 & 16.55 & 9.36 & 4.36 & 3.27 & 5.12 & 06 & $6 \quad 7.06$ & $2.8 \mathrm{~s}$ & $9 \quad 7.34$ & 3.23 & 13.06 & 4.1 & 13.12 & \\
\hline A18.6 & 6.11 & 5.47 & 5.64 & 9.76 & 4. & 3.07 & 3.37 & 6. & 9.28 & 2.83 & $\begin{array}{ll}3 & 9.69\end{array}$ & 3.11 & 5.62 & 3.86 & 4.97 & \\
\hline A11.1 & 10.53 & 4.58 & 9.52 & & 5.29 & 2.96 & 5.66 & 6. & 1.08 & $2.7 \mathrm{~s}$ & $9 \quad 0.60$ & 9 & 8.47 & 3.71 & 8.39 & \\
\hline & 11.90 & 4.51 & 13.95 & & & 2.91 & 5.85 & & & 2.81 & $1 \quad 1.47$ & & 3 & .72 & 9.42 & \\
\hline & & 4.46 & 5.47 & & & 2.86 & 11.75 & & 5 & $2.7 \mathrm{~s}$ & $\begin{array}{l}9 \\
9\end{array}$ & & & 3.58 & 13.10 & \\
\hline A & 3. & 4. & 6.08 & & & 2.84 & & & & 2.77 & 2.41 & & & 5 & 10.42 & \\
\hline & 2. & 4. & 00 & & & 4 & & & & .76 & 3.56 & & 3 & 55 & 1.13 & \\
\hline A & 0.97 & 4.40 & 2.0 & & & 2.83 & 2.14 & & 44 & 2.76 & 3.19 & & .88 & 32 & 7.39 & \\
\hline A & 11.68 & 4.4 & 5.56 & & & 2.8 & 3.44 & & 1 & 2.75 & 1.36 & & 1. & 3.5 & 5.33 & \\
\hline & 38 & 4.36 & 8.02 & 1. & & 2.78 & 1.53 & 5.62 & 0.86 & 2.74 & $4 \quad 0.76$ & 2. & 2. & 3.48 & 3.59 & 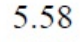 \\
\hline & 7.05 & 4.16 & .50 & 7.06 & & 2.58 & 2.24 & 4.65 & 6.12 & 2.6 & 5.44 & 2.82 & .05 & 3.24 & 3.20 & 4. \\
\hline & .30 & 4.10 & VIF & & & 2.50 & VIF & & $T$. & 2.56 & 6 VIF & & & 3.10 & VIF & \\
\hline 05 & & 48 & VIF & & & 1.96 & VIF & VI & & 2 & VIF & & & & VIF & \\
\hline \multirow{3}{*}{$\begin{array}{l}\text { Station } \\
\text { Length } \\
\end{array}$} & \multicolumn{4}{|c|}{ San Francisco } & \multicolumn{4}{|c|}{ Honolulu } & \multicolumn{4}{|c|}{ DE Cuxhaven } & \multirow{2}{*}{\multicolumn{4}{|c|}{ DE Den Helde }} \\
\hline & & & & & & 105 & & & & & & & & & & \\
\hline & E & $\sigma$ & E & 0 & E & $\sigma$ & E & $\sigma$ & 工 & $\sigma$ & E & 0 & E & $\sigma$ & E & $\sigma$ \\
\hline$(s)$ & $\mathrm{NA}$ & A & .08 & 02 & 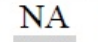 & A & .02 & 02 & & NA & 0.45 & 06 & $\mathrm{~N}$ & NA & 26 & \\
\hline ocity & 1.41 & 0.07 & 1.37 & 0.08 & 1.59 & 22 & .46 &  & & 08 & 50 & .12 & 0 & .07 & .40 & \\
\hline A74.5 & 14.99 & 4.16 & 17.24 & 4.74 & .73 & 13.30 & VIF & VIF & 88 & 5.29 & 31.78 & 6.82 & .07 & 4.21 & 9.69 & 6 \\
\hline A55.8 & 17.66 & 4.37 & 19.4 & 4.93 & 52 & 12.36 & 3.41 & 5.4 & 67 & 5.61 & 18.90 & 7.2 & .75 & 4.06 & 5.62 & 5 \\
\hline 7.2 & 6.34 & 0 & 31 & 4.34 & & 4 & 1.22 & 5.57 & 67 & 5.23 & 4.29 & 6. & 0 & 60 & 56 & 5. \\
\hline & 5.67 & 3.8 & 4.62 & 4.29 & 55 & 6 & 15 & 5.28 & 5 & 5.21 & 10.59 & 6.3 & 7 & .62 & 20 & 5 \\
\hline A & 4.57 & 3. & 5.28 & 4. & & 4 & 11.04 & 5 & & 19 & 96 & 6.39 & 12.31 & 56 & 12.45 & 5 \\
\hline & & & 6. & & & & & & & & & & & & 2 & \\
\hline & & & & & & & 00 & & & 07 & 02 & & & 53 & 24 & \\
\hline & 4 & 3.6 & 5.05 & 4. & & & 7. & 4 & 93 & 05 & 14.49 & 6. & 7.98 & 49 & .81 & \\
\hline & 8. & 3.6 & 8.26 & 4. & & & 6.37 & 4 & & 03 & 6.72 & 6. & 7.43 & 47 & 5.59 & \\
\hline & 6.49 & 3.59 & 8.22 & 3.98 & 43 & 2 & 14.49 & 4 & & 5.04 & 64 & 6. & 4.03 & .49 & 3.54 & 5 \\
\hline & 5 & & 7.06 & 3. & & & 3.92 & 4. & 5 & 5.03 & 13.10 & 6. & 6.74 & 3.47 & 6.28 & 5 \\
\hline & 3.36 & 3.4 & 3.02 & 3. & & & 3.07 & 4. & 7.93 & 5.02 & 9.60 & 6 & 6.16 & 3.48 & 5.43 & 5.17 \\
\hline & 7.21 & 3. & 7.36 & 3 & 6.81 & 44 & 6.06 & 4. & 8.33 & 5.02 & 7.17 & 6.15 & 4.36 & 3.46 & 4.26 & 15 \\
\hline & 4.72 & 2.82 & 5.48 & 3.13 & 3.29 & .78 & 3.28 & 3.17 & & 4.98 & 2.26 & 6.01 & 28 & 3.44 & 4.78 & 4.94 \\
\hline & 198 & 2.0 & VIF & & & 2.51 & VIF & VIF & 92.57 & 4.96 & VIF & VIF & 90.78 & 3.42 & VIF & VIF \\
\hline A0.5 & & 1.70 & VIF & VIF & 10.13 & 1.49 & VIF & VIF & 18.91 & 4.75 & VIF & VIF & 12.68 & 3.28 & VIF & VIF \\
\hline
\end{tabular}


Table 3: (Continued)

\begin{tabular}{|c|c|c|c|c|c|c|c|c|c|c|c|c|c|c|c|c|}
\hline $\begin{array}{l}\text { Station } \\
\text { Length }\end{array}$ & \multicolumn{4}{|c|}{$\begin{array}{c}\text { DE Travemunde } \\
154 \mathrm{yr}\end{array}$} & \multicolumn{4}{|c|}{$\begin{array}{c}\text { FR Brest } \\
202 \mathrm{yr}\end{array}$} & \multicolumn{4}{|c|}{$\begin{array}{c}\text { NL AmsIjmuiden } \\
140 \mathrm{yr}\end{array}$} & \multicolumn{4}{|c|}{$\begin{array}{c}\text { NL Delfzjil } \\
156 \mathrm{yr}\end{array}$} \\
\hline & $E$ & $\sigma$ & $E$ & $\sigma$ & $E$ & $\sigma$ & $E$ & $\sigma$ & $\mathrm{E}$ & $\sigma$ & $E$ & $\sigma$ & $E$ & $\sigma$ & $E$ & $\bar{\sigma}$ \\
\hline IB $(s)$ & NA & NA & 0.20 & 0.03 & NA & NA & 0.02 & 0.04 & NA & NA & 0.31 & 0.04 & NA & NA & 0.34 & 0.05 \\
\hline Velocity & 1.64 & 0.05 & 1.63 & 0.07 & 1.02 & 0.04 & 1.34 & 0.09 & 1.83 & 0.08 & 1.77 & 0.10 & 1.70 & 0.08 & 1.69 & 0.11 \\
\hline A74.5 & 4.44 & 3.32 & 5.19 & 4.01 & 7.19 & 3.27 & 24.53 & 5.93 & 27.17 & 4.72 & 26.45 & 5.99 & 11.10 & 5.22 & 11.03 & 6.96 \\
\hline A55.8 & 8.90 & 3.45 & 9.24 & 4.10 & 8.85 & 3.56 & 9.73 & 5.19 & 18.31 & 4.66 & 21.45 & 6.26 & 11.13 & 4.91 & 10.18 & 6.13 \\
\hline A37.2 & 5.23 & 2.99 & 5.97 & 3.58 & 15.21 & 3.38 & 12.64 & 4.91 & 19.26 & 4.02 & 20.53 & 28 & 3.90 & 4.47 & 3.28 & 5.6 \\
\hline A22.0 & 4.85 & 2.93 & 5.29 & 3.58 & 6.82 & 3.5 & 3.12 & 4.74 & 12.27 & 4.01 & 11.65 & 5.15 & 7.64 & 4.49 & 8.07 & 5.54 \\
\hline A18.6 & 4.18 & 3.01 & 3.32 & 3.57 & 6.46 & 3.35 & 10.43 & 4.79 & 19.10 & 4.00 & 17.29 & 5.17 & 14.74 & 4.42 & 14.71 & 5.41 \\
\hline A11.1 & 8.34 & 2.92 & 8.34 & 3.50 & 3.86 & 3.27 & 6.89 & 4.58 & 8.73 & 3.94 & 10.57 & 5.11 & 13.56 & 4.39 & 13.96 & 5.42 \\
\hline A9.3 & 3.13 & 2.9 & 2.90 & 3.47 & 8.14 & 3.29 & 8.36 & 4.64 & 3.20 & 3.96 & 1.35 & 5.1 & 6.92 & 4.37 & 6.31 & 5.39 \\
\hline A6.2 & 8.77 & 2.9 & 8.64 & 3.44 & 5.43 & 3.21 & 4.32 & 4.5 & 9.29 & 3.91 & 10.03 & 5.06 & 10.85 & 4.33 & 10.91 & 5.36 \\
\hline A 4.7 & 4.96 & 2.88 & 3.19 & 3.44 & 3.69 & 3.22 & 6.64 & 4.48 & 8.04 & 3.9 & 6.49 & 5.07 & 5.49 & 4.32 & 3.48 & 5.36 \\
\hline A3.7 & 4.26 & 2.88 & 2.70 & 3.44 & 4.59 & 3.2 & 5.71 & 4.44 & 2.36 & 3.9 & 1.76 & 5.04 & 7.81 & 4.33 & 7.76 & 5.34 \\
\hline A3.1 & 7.19 & 2.88 & 6.08 & 3.43 & 3.22 & 3.19 & 2.58 & 4.45 & 8.41 & 3.89 & 8.49 & 5.02 & 10.09 & 4.31 & 9.77 & 5.32 \\
\hline A2. 6 & 2.84 & 2.88 & 1.63 & 3.43 & 6.63 & 3.19 & 4.75 & 4.4 & 2.44 & 3.88 & 1.28 & 5.00 & 7.82 & 4.32 & 6.97 & 5.31 \\
\hline A 2.3 & 4.25 & 2.88 & 3.55 & 3.42 & 3.34 & 3.17 & 2.06 & 4.37 & 5.96 & 3.87 & 5.70 & 5.00 & 6.21 & 4.31 & 5.72 & 5.3 \\
\hline A1.2 & 3.16 & 2.85 & 4.15 & 3.35 & 4.68 & 3.04 & 6.84 & 4.06 & 3.90 & 3.79 & 4.95 & 4.79 & 4.01 & 4.27 & 5.33 & 5.19 \\
\hline A 1.0 & 37.73 & 2.83 & VIF & VIF & 49.89 & 2.97 & VIF & VIF & 82.9 & 3.75 & VIF & VIF & 78.31 & 4.25 & VIF & VIF \\
\hline A 0.5 & 17.81 & 2.72 & VIF & VIF & 19.65 & 2.53 & VIF & VIF & 12.22 & 3.40 & VIF & VIF & 14.83 & 4.07 & VIF & VIF \\
\hline
\end{tabular}

\begin{tabular}{|c|c|c|c|c|c|c|c|c|c|c|c|c|c|c|c|c|}
\hline \multirow[t]{2}{*}{$\begin{array}{l}\text { Station } \\
\text { Length }\end{array}$} & \multicolumn{4}{|c|}{$\begin{array}{c}\text { NL Harlingen } \\
146 \mathrm{yr}\end{array}$} & \multicolumn{4}{|c|}{$\begin{array}{c}\text { NL Terscelling } \\
90 \mathrm{yr}\end{array}$} & \multicolumn{4}{|c|}{$\begin{array}{c}\text { PL Swinoujscie } \\
189 \mathrm{yr}\end{array}$} & \multicolumn{4}{|c|}{$\begin{array}{c}\text { SE Landsort } \\
123 \mathrm{yr}\end{array}$} \\
\hline & E & $\sigma$ & E & $\sigma$ & E & $\sigma$ & E & $\sigma$ & E & $\sigma$ & $\mathrm{E}$ & $\sigma$ & E & $\sigma$ & E & $\sigma$ \\
\hline IB $(s)$ & NA & NA & 0.31 & 0.05 & NA & NA & 0.24 & 0.06 & NA & NA & 0.21 & 0.04 & NA & $\mathrm{NA}$ & 0.14 & 0.07 \\
\hline Velocity & 1.28 & 0.08 & 1.2 & 1 & 1.51 & 0.89 & 0.73 & 3 & 0.80 & 0.06 & 1 & 1 & 89 & 0.16 & -2.89 & 3 \\
\hline A & 10.67 & 5.21 & 3 & 6.51 & 77 & 45.99 & VIF & & 6 & 4.86 & 1 & & 2.7 & 10 & 77 & \\
\hline A & 6.25 & 5.23 & 5.97 & 6.66 & 43 & 39.53 & 15.17 & 3 & 3 & 4.62 & & 6.95 & 77 & 9.72 & 33 & \\
\hline A & 5.44 & 4.46 & 9 & 5. & 1.23 & 10.24 & 14.1 & 5 & 5.71 & 4. & 10. & 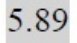 & 6.70 & 7.80 & 6.95 & \\
\hline $\mathrm{A}^{2}$ & VIF & VIF & 5.02 & 5.6 & 9.18 & 5.8 & 9.7 & 5 & 1 & 4.57 & 11.36 & 5.82 & 7 & 7.74 & 10.88 & 1 \\
\hline A18.6 & 12.24 & 4.38 & 12.24 & 5.5 & .00 & 5.8 & 13.59 & 5 & 3.68 & 4.58 & 4.8 & 4 & 7 & 7.77 & 10.91 & 10 \\
\hline A11.1 & 8.08 & 4.36 & 8.92 & 5.5 & 4.11 & 5.1 & 6.55 & 7.63 & 16.29 & 4.48 & 13.09 & 7 & 10.79 & 7.78 & 11.69 & 10 \\
\hline A9.3 & 8.09 & 4.37 & 7.31 & 5.51 & 7.39 & 5.06 & 6.73 & 7.58 & 7.41 & 4.47 & 9.35 & 5.73 & 14.33 & 7.63 & 12.30 & 10 \\
\hline A6.2 & 9.93 & 4.32 & 10.69 & 5.4 & 5.75 & 4.85 & 15.7 & 7.41 & 6.72 & 4.43 & 10.07 & 5.68 & 19.40 & 7.64 & 20.99 & 10 \\
\hline A4 4.7 & 8.77 & 4.3 & 6.41 & 5.4 & 5.82 & 4.81 & 2.91 & 7.3 & 7.4 & 4.42 & 6.97 & 5.67 & 7.35 & 7.62 & 7.18 & 10 \\
\hline A3.7 & 1.85 & 4.32 & 0.67 & 5. & 2.46 & 4.83 & 2.35 & 7. & 6.07 & 4.41 & 6.4 & 5.6 & 0.22 & 7.6 & 3.57 & 10 \\
\hline A & 9.59 & 4.3 & 9.28 & 5.44 & 15.41 & 4.79 & 15.19 & 7.33 & 9.64 & 4.4 & .83 & 5.63 & 20.38 & 7.54 & 19.74 & (9) \\
\hline A & 7.01 & 4.31 & 5.97 & 5.43 & 77 & 4.8 & 6.6 & 7.32 & 4.82 & 4.38 & 1.65 & 59 & 5.89 & 7.52 & 14.38 & 8 \\
\hline 3 & 6.08 & 4.3 & 5.6 & 5.43 & 10.01 & 4.8 & 9.4 & 8 & 3.7 & 4.36 & 2.13 & 6 & 3 & 7.46 & 6.91 & .7 \\
\hline 2 & 2.85 & 4.26 & 3.88 & 5.3 & 04 & 4.74 & 12.71 & .96 & 1.9 & 4.18 & . & & 2.81 & 6.94 & 4.57 & 8.6 \\
\hline A1.0 & 90.2 & 4.24 & VIF & VIF & 98.99 & 4.71 & VIF & VIF & 49.39 & 4.1 & VIF & VIF & 93.29 & 6.72 & VIF & VIF \\
\hline A 0.5 & 13.52 & 4.06 & VIF & VIF & 14.35 & 4.52 & VIF & VIF & 30.53 & 3.49 & VIF & VIF & 46.35 & 5.27 & VIF & VIF \\
\hline
\end{tabular}


Table 3: (Continued)

\begin{tabular}{|c|c|c|c|c|c|c|c|c|c|c|c|c|c|c|c|c|}
\hline \multirow[t]{2}{*}{$\begin{array}{l}\text { Station } \\
\text { Length }\end{array}$} & \multicolumn{4}{|c|}{ SE Stockholm } & \multicolumn{4}{|c|}{ UK Liverpool } & \multicolumn{4}{|c|}{$\begin{array}{l}\text { UK N. Shields } \\
115 \mathrm{yr}\end{array}$} & \multicolumn{4}{|c|}{$\begin{array}{c}\text { AU Sydney } \\
96 \mathrm{yr}\end{array}$} \\
\hline & $E$ & $\sigma$ & $\mathrm{E}$ & $\sigma$ & $E$ & $\bar{\sigma}$ & $\mathrm{E}$ & $\sigma$ & $E$ & $\sigma$ & E & $\sigma$ & $\mathrm{E}$ & $\sigma$ & $\mathrm{E}$ & 0 \\
\hline IB $(s)$ & NA & $\mathrm{TA}$ & 0.19 & .07 & NA & NA & & .08 & NA & NA & 0.1 & & & NA & 10 & \\
\hline & .85 & 17 & -3.86 & & 85 & 0 & & & & 0.08 & 2.02 & & & .27 & .04 & \\
\hline & 18.41 & 10.42 & 18.18 & 1 & 15.95 & 6.90 & & & & 4.53 & 5.21 & & & 12.07 & $\sqrt{ } 1$ & \\
\hline & 15.39 & 10.12 & 13.45 & 15.15 & 22 & 5.74 & & & 8.84 & 4.32 & 11.22 & 12. & 16.59 & 6.95 & 13.11 & \\
\hline & & 8. & 6.07 & & 18.42 & 5.88 & & & & 3.29 & 9.61 & & & .64 & 7.27 & \\
\hline & & 97 & 86 & & &  & & & & 3.19 & 4.2 & & & 15 & & \\
\hline & & 94 & 3 & & & & & & & 3 & & & & 9 & & \\
\hline & & 95 & & & & & & & & & & & & & & \\
\hline & & & & & & 9 & & & & & & & & & & \\
\hline & & 86 & 5 & & & T & & & & 3.10 & 5.1 & & & & & \\
\hline & & f & 78 & & & & & & & 3.11 & 2.43 & & & $p$ & 1 & \\
\hline & & 7. & 90 & & & 4.69 & & & & 3.12 & 2.0 & & & 2.81 & .71 & \\
\hline & & 76 & 9.92 & & 12 & 4.72 & & & & .09 & 3.1 & & & 2. & 3 & \\
\hline & & 71 & 14.04 & & & 4.68 & & & & 3.0 & 2. & & & 2.79 & 4.01 & 3. \\
\hline & & 65 & 6.9 & & & 4. & & & & 3.05 & 5. & & & 8 & 3.3 & 3. \\
\hline & & & 4. & & 4.40 & 4.49 & & & & 2.93 & 5.41 & & & 5 & 4.3 & \\
\hline & & 88 & IF & & & 4. & & & & 2.87 & 3.2 & & & VIF & $\sqrt{2}$ & \\
\hline & & 4 & IF & & & 4.02 & 9.34 & 4.94 & 1.15 & 2.44 & VIF & $\sqrt{15}$ & 22.43 & 2.21 & VIF & VII \\
\hline
\end{tabular}

\begin{tabular}{cccccccccccccc}
\hline $\begin{array}{c}\text { Station } \\
\text { Length }\end{array}$ & \multicolumn{3}{c}{$\begin{array}{c}\text { CA Ketchikan } \\
91\end{array}$} & \multicolumn{4}{c}{ yr } & \multicolumn{4}{c}{ CA Prince Rupert } & \multicolumn{4}{c}{ IN Mumbai } \\
\hline & E & $\sigma$ & E & $\sigma$ & E & $\sigma$ & E & $\sigma$ & E & $\sigma$ & E & $\sigma$ \\
\hline IB (s) & NA & NA & 0.89 & 0.08 & NA & NA & 1.23 & 0.09 & NA & NA & 0.11 & 0.03 \\
Velocity & -0.09 & 0.64 & -0.12 & 0.23 & -0.08 & 0.59 & -0.35 & 0.79 & 0.82 & 0.05 & 0.85 & 0.06 \\
A74.5 & 18.73 & 15.1 & VIF & VIF & 78.56 & 23.48 & 88.96 & 31.35 & 29.01 & 3.18 & 28.25 & 3.74 \\
A55.8 & 22.2 & 16.02 & 4.68 & 8.36 & 68.86 & 29.38 & 83.24 & 39.3 & 5.97 & 3.18 & 7.92 & 3.88 \\
A37.2 & 8.15 & 7.62 & 8.6 & 9.09 & 23.55 & 14.5 & 31.9 & 19.45 & 6.87 & 2.53 & 5.95 & 2.98 \\
A22.0 & 8.88 & 5.12 & 9.33 & 8.58 & 19.77 & 7.09 & 23.34 & 9.42 & 6.52 & 2.3 & 6.58 & 2.62 \\
A18.6 & 3.07 & 5.27 & 4.95 & 8.22 & 6.78 & 7.13 & 8.99 & 9.66 & 9.45 & 2.30 & 9.72 & 2.63 \\
A11.1 & 4.30 & 4.64 & 5.87 & 7.67 & 8.31 & 4.99 & 9.02 & 6.67 & 3.00 & 2.30 & 2.49 & 2.64 \\
A9.3 & 10.11 & 4.64 & 11.75 & 7.8 & 6.06 & 4.87 & 6.87 & 6.51 & 3.51 & 2.31 & 3.56 & 2.65 \\
A6.2 & 5.08 & 4.57 & 5.13 & 7.53 & 0.26 & 4.86 & 0.46 & 6.46 & 4.64 & 2.31 & 4.14 & 2.64 \\
A4.7 & 14.35 & 4.52 & 15.22 & 7.47 & 14.7 & 4.78 & 14.00 & 6.36 & 4.63 & 2.3 & 5.25 & 2.64 \\
A3.7 & 4.93 & 4.5 & 4.60 & 7.41 & 4.61 & 4.79 & 5.56 & 6.36 & 5.63 & 2.29 & 5.21 & 2.63 \\
A3.1 & 3.03 & 4.47 & 1.62 & 7.33 & 6.59 & 4.78 & 7.02 & 6.29 & 3.77 & 2.29 & 3.69 & 2.63 \\
A2.6 & 7.32 & 4.46 & 10.73 & 7.26 & 11.95 & 4.77 & 11.84 & 6.3 & 2.30 & 2.28 & 2.41 & 2.63 \\
A2.3 & 5.23 & 4.43 & 3.99 & 7.15 & 4.96 & 4.72 & 4.05 & 6.22 & 2.50 & 2.28 & 2.31 & 2.61 \\
A1.2 & 13.91 & 4.23 & 9.59 & 6.32 & 12.59 & 4.48 & 12.66 & 5.73 & 6.61 & 2.23 & 6.65 & 2.55 \\
A1.0 & 107.83 & 4.17 & VIF & VIF & 109.8 & 4.41 & VIF & VIF & 23.91 & 2.2 & VIF & VIF \\
A0.5 & 24.68 & 3.54 & VIF & VIF & 24.16 & 3.74 & VIF & VIF & 33.2 & 2.0 & VIF & VIF \\
\hline
\end{tabular}


time series improves the uncertainties of the estimated sea level trends by $10-30 \%$, and advocate using of IB effect as a correction for the tide gauge records. However, correcting the impact of atmospheric pressure through IB effect on the sea level variations as is may also lead to erroneous inferences for satellite altimetry studies. The estimated scale factors for the IB effect established that the sea level response to the atmospheric pressure changes is strongly location dependent. IB effects, as corrections, will bias the magnitude of the low frequency sea level variations if their impacts are not scaled as a function of the location of the observations, which also explains the range for reported percentage improvements. This error source can be avoided if the IB effect is parametrized and adjusted for, using the observed atmospheric pressure data in pertinent studies together with the other variables.

Acknowledgement: Critical comments by two anonymous reviewers are gratefully acknowledged.

\section{References}

Allan, R. J., and T. J. Ansell, 2006, A new globally-complete monthly historical gridded mean sea level pressure data set (HadSLP2): 1850-2004. J. Clim., 19, 5816-5842.

Bindoff, N.L., J. Willebrand, V. Artale, A, Cazenave, J. Gregory, S. Gulev, K. Hanawa, C. Le Quéré, S. Levitus, Y. Nojiri, C.K. Shum, L.D. Talley and A. Unnikrishnan, 2007, Observations: Oceanic Climate Change and Sea Level. In: Climate Change 2007: The Physical Science Basis. Contribution of Working Group I to the Fourth Assessment Report of the Intergovernmental Panel on Climate Change [Solomon, S., D. Qin, M. Manning, Z. Chen, M. Marquis, K.B. Averyt, M. Tignor and H.L. Miller (eds.)]. Cambridge University Press, Cambridge, United Kingdom and New York, NY, USA.

Chelton, D. B., and R. E. Davis, 1982, Monthly mean sea-level variability along the west coast of North America. J. Phys. Oceanogr., 12, 757-784.

Douglas, B. C., 2008, Concerning evidence for fingerprints of glacial melting. Journal of Coastal Research, 24(2B), 218-227.

Gaspar, P., and R.M. Ponte, 1997, Relation between sea level and barometric pressure determined from altimeter data and model simulations. J. Geophys. Res., 102, 961- 971.

Gillett, N. P., F. W. Zwiers, A. J. Weaver, and P. A. Stott, 2003, Detection of human influence on sea-level pressure. Nature, 422, 292-294.

Keeling, C. D., and Whorf T. P., 1997, Possible forcing of global temperature by oceanic tides. Proc. Natl. Acad. Sci., 94, 8321-8328.

Hamon, B. V., 1962, The spectrum of mean sea level at Sydney, Coff's Harbor, and Lord Howe Island. J. Geophys. Res., 67, 5147-5155.

İz H.B., 2016a, Thermosteric contribution of warming oceans to the global sea level variations, J. Geod. Sci., Vol. 6, pp. 130-138.

İz H.B., 2016b, The effect of warming oceans at a tide gauge station, J. of Geod. Sci., Vol. 6, pp. 69-79.

İz H.B., 2015, More confounders at global and decadal scales in detecting recent sea level accelerations, J. of Geod. Sci, 5, 192-198.
İz H.B., 2014, Sub and super harmonics of the lunar nodal tides and the solar radiative forcing in global sea level changes, J. of Geod. Sci., 4, 150-165.

İz H.B., L. Berry, and M. Koch, 2012, Modeling regional sea level rise using local tide gauge data, J. of Geod. Sci., Vol. 2, Issue 3, pp. 188-1999.

İz H.B., 2006, How do unmodeled systematic MSL variations affect long term sea level trend estimates from tide gauge data? J. of Geodesy, Vol. 80, No.1, pp. 40-46.

Kuo, 2017, Private communication.

Lisitzin, E., 1974, Sea-level changes, Elsevier Oceanography Series, 8. Amsterdam: Elsevier, 286 pp.

Munk, W., Dzieciuch M., Jayne S., 2002, Millennial Climate Variability: Is There a Tidal Connection? J. Climate, 15, 370-385.

Piecuch, C. G., P. R. Thompson, and K. A. Donohue (2016), Air pressure effects on sea level changes during the twentieth century, J. Geophys. Res. Oceans, 121, 7917-7930.

Ponte, R. M., D. A. Salstein, and R. D. Rosen, (1991), Sea level response to pressure forcing in a barotropic numerical model. J. Phys. Oceanogr., 21, 1043-1957.

Ponte, R. M., and P. Gaspar, 1999, Regional analysis of the inverted barometer effect over the global ocean using TOPEX/POSEIDON data and model results, J. Geophys. Res., 104(C7), 15,587-15,601.

Ponte R. M., 2006, Low-Frequency Sea Level Variability and the Inverted Barometer Effect, J. of Atmospheric and Oceanic Tech., 23, 619-629.

Robinson, A. R., 1964, Continental shelf waves and the response of sea level to weather systems. J. Geophys. Res., 69, 367-368.

Roden G. I., 1966, Low frequency sea level oscillations along the Pacific coast of North America. J. Geophys. Res., 71, 4755-4775.

Roden, G. I., (1960), On the nonseasonal variations in sea level along the west coast of North America. J. Geophys. Res., 65, 2809-2826.

Stammer, D., S., Hüttemann, (2008), Response of Regional Sea Level to Atmospheric Pressure Loading in a Climate Change Scenario, Journal of Climate, vol. 21, issue 10, p. 2093.

Tai, C.-K., 1993, On the quasigeostrophic oceanic response to atmospheric pressure forcing: The inverted barometer pumping, NOAA Tech. Memo. NOS OES 005, 19 pp., Nat. Oceanic and Atmos. Admin. Nat. Ocean Serv., Rockville, MD.

Treloar, N. C., 2002, Luni-Solar Tidal Influences on Climate Variability, Int. J. Climatol. 22: 1527-1542.

Trupin, A., and J. Wahr, (1990), Spectroscopic analysis of global tide gauge sea level data. Geophys. Jint., 100, 441-453.

Wunsch, C., 1972, Bermuda sea level in relation to tides, weather, and baroclinic fluctuations. Rev. Geophys., 10, 1-49., 1991: Large-scale response of the ocean to atmospheric forcing at low frequencies. J. Geophys. Res., 96, 15083-15092. 